\title{
Innovative Approach for the Use of Huwa-San TR50 in Controlling Cotton Aphids (Aphis gossypii Glover)
}

\author{
Saleh S. Alhewairini ${ }^{1}$ \\ ${ }^{1}$ Department of Plant Production and Protection, College of Agriculture and Veterinary Medicine, Qassim \\ University, Al-Qassim, Saudi Arabia \\ Correspondence: Saleh S. Alhewairini, Department of Plant Production and Protection, College of Agriculture \\ and Veterinary Medicine, Qassim University, P.O. Box 6622, Buraidah 51452, Al-Qassim, Saudi Arabia. Tel: \\ 966-163-801-360. E-mail: hoierieny@qu.edu.sa
}

Received: January 10, 2017

Accepted: February 6, 2017 Online Published: March 15, 2017

doi:10.5539/jas.v9n4p77

URL: https://doi.org/10.5539/jas.v9n4p77

\begin{abstract}
Chemical control remains the main method of controlling the cotton aphid (Aphis gossypii Glover). Millions of dollars have been lost due to plant damage which resulted in reduced quality and yield of cotton. Nevertheless, $A$. gossypii can rapidly develop resistance to different groups of insecticides such as organophosphates, carbamates and pyrethroids. The potential of Huwa-San TR50 in controlling A. gossypii is yet to be tested. Huwa-San TR50 is a formula of hydrogen peroxide which has been stabilized by the addition of a small quantity of silver and has extensively used as a disinfectant. In this study, it was found to be very potent in killing A. gossypii and produced 93.5, 96.5, 97 and 95.5\% mortality at 1000, 2000, 3000 and 4000 ppm, respectively, after $48 \mathrm{~h}$ of exposure. Furthermore, there was no significant difference between four Huwa-San TR50 concentrations after $48 \mathrm{~h}$ of exposure, on the mortality of A. gossypii. Huwa-San TR50 of up to $4000 \mathrm{ppm}$ had no observable effects on the mortality and behavior of adult honeybee workers (Apis mellifera lamarckii) as compared with the control. Also, Huwa-San TR50 concentration of up to $3000 \mathrm{ppm}$ had no observable effect on seven-spot ladybird beetles (Coccinella septempunctata) whereas a concentration of $4000 \mathrm{ppm}$ produced $100 \%$ mortality after $24 \mathrm{~h}$ of exposure. Huwa-San TR50 concentrations of up to $2000 \mathrm{ppm}$ failed to produce any symptoms on cucumber leaves. The differential effects of Huwa-San TR50 on aphids and beneficial insects, suggest the need for further investigation to understand the effects of Huwa-San TR50 on other host plants of aphids and aphid species.
\end{abstract}

Keywords: Huwa-San TR50, aphids, Aphis gossypii Glover, honeybees, ladybird beetles

\section{Introduction}

The cotton aphid (Aphis gossypii Glover) is a serious insect pest in horticulture, agriculture and greenhouse crops (Aheer et al., 2006; Khattak et al., 2007). This is because more than 320 suitable host plants belonging to 46 families worldwide have been reported as hosts of A. gossypii (Blackman \& Eastop, 2000). It has also been considered as an important pest of cotton, as a result of the high economic losses of cotton recorded (Ebrt \& Cartwright, 1997). In California for example, cotton infestation by A. gossypii in the mid- or late season, can significantly reduce both cotton yield and lint quality (Godfrey \& Fuson, 2001) and is responsible for about US \$24 million in crop loss and another US \$ 38 million in control costs (Godfrey \& Fuson, 2001). This pest can also infest plants at the beginning of the cropping season. Plants infested by A. gossypii show reduced development, especially in young leaves which are responsible for driving the main stem and/or branches (Leclant \& Deguine, 1994; Ebert, 2008). This includes direct damage to the plant, honeydew on the plant leaves and open lint which can result in a decline in the quality and yield of cotton by promoting the growth of black sooty mold fungus that causes problems during spinning (Deguine et al., 2000).

In cotton fields, A. gossypii is primarily controlled by seed treatment or foliar spraying of insecticides (systemic or broad-spectrum) (Almeida et al., 2008; Torres \& Silva-Torres, 2008). In organic farming, the biological control (predatory and parasitic insects) of A. gossypii is effective at low density (Kaleem et al., 2014) but can be less effective under adverse environmental conditions (Godfrey \& Fuson, 2001; Kaleem et al., 2014), e.g. reduced populations of natural enemies (Grafton-Cardwell et al., 1997). This results in an increase in the difficulty of controlling many pests including A. gossypii (Pinto et al., 2013). 
Insecticides remain the primary tool for growers in controlling A. gossypii. Nevertheless, A. gossypii can rapidly develop resistance to several insecticides, making the control of $A$. gossypii difficult and ineffective (Godfrey \& Fuson, 2001). Previous studies have reported the resistance of $A$. gossypii to insecticides (Funk et al., 1980; Takada \& Murakami, 1988; Grafton-Cardwell et al., 1992; Guburn et al., 1992). This resistance to organophosphates, carbamate and pyrethroids has developed in many parts of the world including China (Sun et al., 1987; Zheng et al., 1988), Japan (Saito, 1989; Hama et al., 1995), the United States (Grafton-Cardwell et al., 1991; Hollingsworth et al., 1994), Israel (Ishaaya \& Mendelson, 1987), the United Kingdom (Funk et al., 1980; Funk et al., 1993) and Sudan (Guburn et al., 1992). In the San Joaquin Valley of California, Grafton-Cardwell et al. (1991) reported a temporal and spatial variation in susceptibility to selected organochlorine and organophosphate.

In agricultural greenhouses, insect pest management has extensively been used for both natural enemies (mainly in biological control) and insecticides. The latter has widely been used as a simple tool to control a wide range of insect pests without thinking about the serious damage they might produce in both natural enemies and beneficial insects. Furthermore, the extensive use, misuse and/or unnecessary application of insecticides at the early season might result in a reduction in the population of natural enemies as well as beneficial insects. Widespread concern has been expressed about the exposure of honeybees to insecticides by direct contact or indirect residues in nectar and/or pollen. For example, an acute risk to honeybees was identified from exposure to neonicotinoid insecticide residues in nectar and pollen or dust from seed treatment in maize, cereal and oil-seeds (European Food Safety Authority, 2013).

Ladybird beetles are very effective in controlling aphids (Seo \& Youn, 2000, 2002), however, the use of insecticides such as imidacloprid and acetamiprid at the recommended field rate for aphid control has been reported to kill ladybird beetles (Youn et al., 2003). Ladybird beetles might also be indirectly exposed to insecticide residues after consuming treated aphids (De Cock et al., 1996).

Hence, many insecticides have been banned or restricted in some countries as a result of their toxicity to natural enemies and/or beneficial insects. For example, clothianidin, thiamethoxam and imidacloprid have been restricted in the EU since 2013, due to their high risk to honeybees (EU, 2013). This is because these insecticides are very effective in controlling many insect pests including aphids. These combined problems can make the control and management of $A$. gossypii very difficult.

The literature review has highlighted the need to investigate an alternative strategy for controlling A. gossypii in order to replace the traditional, over used, banned, or restricted insecticides.

There are no previous reports of using Huwa-San TR50 for the control of cotton aphids. Huwa-San TR50 is a formula of hydrogen peroxide which has been stabilized by the addition of a small quantity of silver (www.huwasa.com). Huwa-San TR50 is mainly used as a disinfectant and was developed over twenty years ago (www.huwasa.com). Huwa-SanTR50 has several advantages that make it reliable and safe such as long term effectiveness, high efficacy even at low concentrations, being effective under a wide range of temperatures up to boiling point, gentle to the skin, biodegradable, non-toxic, no build-up of resistance by microorganisms, colorless, odorless and tasteless (www.huwasa.com).

There is no information on the impact of the application of Huwa-San TR50 on pests or beneficial insects. This study aimed to evaluate the potential effectiveness of Huwa-San TR50 against aphids; test the side effects of Huwa-San TR50 on beneficial insect honeybees and ladybird beetles; determine the recommended rate that can be used in the field without any serious leaf malformation.

\section{Method}

Huwa-San TR50 was obtained from Ghatafan Company in Onaizah (retailer agent). The stock solution of Huwa-San TR50 (500,000 ppm) was diluted with distilled water to give a serial concentration range between 1000 to $4000 \mathrm{ppm}$.

Untreated cucumber leaves (Cucumis sativus) (Brenji RZ F1-Hybrid (22-80)) were used to maintain A. gossypii in greenhouses. The experiments in this study were conducted under laboratory and greenhouse conditions.

In greenhouse experiments, four different Huwa-San TR50 concentrations (1000, 2000, 3000 and 4000 ppm) including the control (only distilled water without Huwa-San TR50) were sprayed directly on the cucumber leaves (mid-stage) by using a knapsack sprayer $(20 \mathrm{~L})$.

In the laboratory, cucumber leaves infested by $A$. gossypii were collected from the greenhouse. The number of $A$. gossypii on each leaf was counted. Thereafter, the leaves were distributed in separate containers. Huwa-San TR50 was then sprayed directly on the infected cucumber leaves by using a hand sprayer. The mortality of $A$. gossypii was determined after 24 and $48 \mathrm{~h}$ by counting dead A. gossypii under a microscope. 
Adult worker honeybees (Apis mellifera lamarckii) were obtained from the Agricultural Research Station of Qassim University. The four Huwa-San TR50 concentrations listed above including the control (only distilled water without Huwa-San TR50) and beeswax (as a source of food) were sprayed directly onto 25 honeybees with four replicates for each concentration. Beeswax was included with each treatment including the control (only distilled water without Huwa-San TR50). Beeswax was also exposed to Huwa-San TR50 to determine if it can produce any effect by feeding. The mortality of the honeybees was measured after 24 and $48 \mathrm{~h}$ and the effect on behavior was noted.

Seven-spot ladybird beetles (C. septempunctata) were collected from Alfalfa fields and placed in separate containers containing cucumber leaves infested by A. gossypii, which served as a food source. The four Huwa-San TR50 concentrations listed above including the control (only distilled water without Huwa-San TR50) were sprayed directly on ten ladybird beetles with four replicates for each concentration. The mortality of ladybird beetles was measured after 24 and $48 \mathrm{~h}$ and the behavior was observed.

The mortality of the cotton aphids was calculated manually under a microscope. Also, the mortalities of honeybees and ladybird beetles were calculated manually by direct observation. The collected data for all variables were statistically analyzed using the MSTATC microcomputer program (MSTATC, 1990). Data were then calculated using the Microsoft Excel program. Dilution-response curves for the mortality assay were plotted using Graph pad Prism version 7. Data points were the mean \pm SEM of each concentration and the graphs were fitted using a nonlinear regression with a four parameter logistic equation where the upper plateau was set to $100 \%$ and the lower plateau was set to 0 .

\section{Results}

A. gossypii were exposed to four Huwa-San TR50 concentrations (1000, 2000, 3000 and 4000 ppm) and showed 93.5, 96.5, 97, and 95.5\% mortality, respectively, after $48 \mathrm{~h}$ of exposure as compared with the control. Furthermore, there was no significant difference between the mortality of $A$. gossypii caused by $48 \mathrm{~h}$ exposure to Huwa-San TR50 concentrations of 1000, 2000, 3000 and 4000 ppm. However, there was a significant difference in the mortality percentage between 24 and $48 \mathrm{~h}$ (Figure 1).

Honeybees were also very active and no difference was observed between the treated and non-treated honeybees (control), whether after 24 or $48 \mathrm{~h}$ of exposure at any concentrations tested. Huwa-San TR50 surprisingly had no significant effect on honeybees and ladybird beetles. No significant effect was seen on ladybird beetles up to $3000 \mathrm{ppm}$ whereas at $4000 \mathrm{ppm}$, all ladybird beetles were killed. Huwa-San TR50 did not produce any symptoms on cucumber leaves up to $2000 \mathrm{ppm}$ whereas $3000 \mathrm{ppm}$ and beyond produced detectable leaf malformation after $48 \mathrm{~h}$ of exposure (Figure 2).

Table 2. Percentage mortality of $A$. gossypii after 24 and $48 \mathrm{~h}$ of exposure to Huwa- San TR50. Mean of four replications

\begin{tabular}{lll}
\hline Huwa-San TR50 concentration $(\mathrm{ppm})$ & $24 \mathrm{~h}$ & $48 \mathrm{~h}$ \\
\hline 4000 & $41.5 \mathrm{a}$ & $95.5 \mathrm{a}$ \\
3000 & $36.0 \mathrm{~b}$ & $97.0 \mathrm{a}$ \\
2000 & $42.5 \mathrm{a}$ & $96.5 \mathrm{a}$ \\
1000 & $11.5 \mathrm{c}$ & $93.5 \mathrm{a}$ \\
Control (distilled water) & $1.9 \mathrm{~d}$ & $6.3 \mathrm{~b}$ \\
\hline
\end{tabular}

Table 2. Percentage mortality of ladybird beetles after 24 and $48 \mathrm{~h}$ of exposure to Huwa-San TR50. Mean of four replications

\begin{tabular}{lll}
\hline Huwa-San TR50 concentration (ppm) & $24 \mathrm{~h}$ & $48 \mathrm{~h}$ \\
\hline 4000 & $100 \mathrm{a}$ & $100 \mathrm{a}$ \\
3000 & $13.3 \mathrm{~b}$ & $30.0 \mathrm{~b}$ \\
2000 & $10.0 \mathrm{~b}$ & $16.6 \mathrm{~b}$ \\
1000 & $10.0 \mathrm{~b}$ & $16.6 \mathrm{~b}$ \\
Control (distilled water) & $6.6 \mathrm{~b}$ & $16.6 \mathrm{~b}$ \\
\hline
\end{tabular}




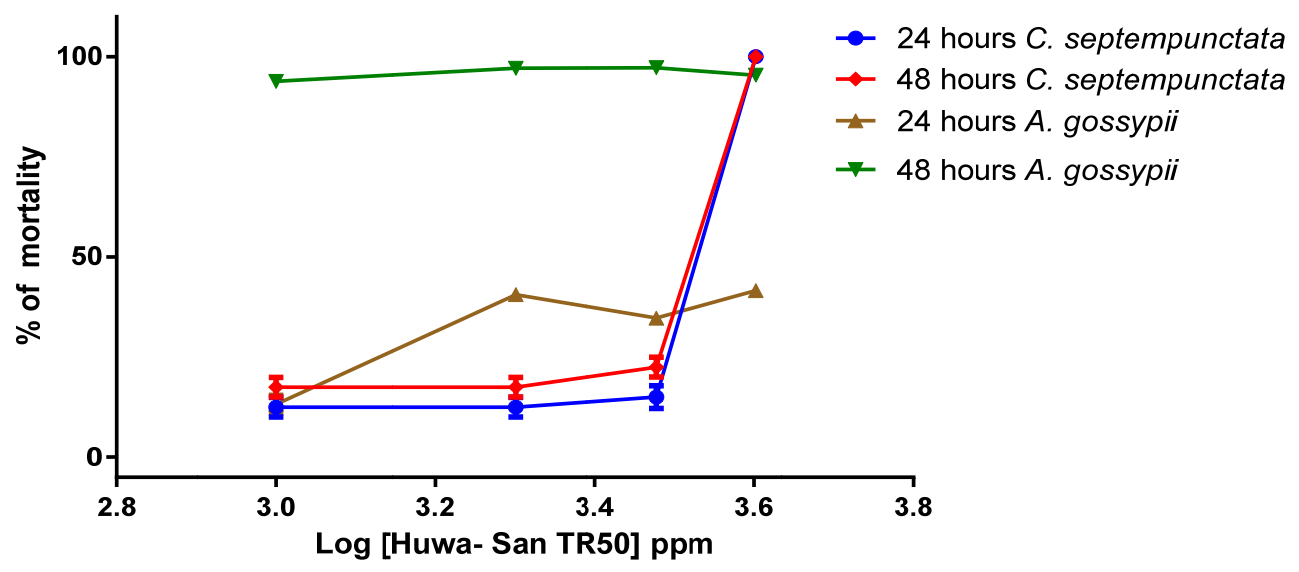

Figure 1. Comparison of the effects of Huwa-San TR50 on the mortality of $A$. gossypii and ladybird beetles $(C$. septempunctata) after 24 and $48 \mathrm{~h}$ of exposure, expressed as a percentage of the control mortality in distilled water. Each point is the mean \pm SEM of 4 replicates, but in most cases the error bars are smaller than the symbols used. The lines were fitted using a non-linear regression in Graph Pad Prism 7 with the maximum plateau being $100 \%$ and the minimum being $0 \%$

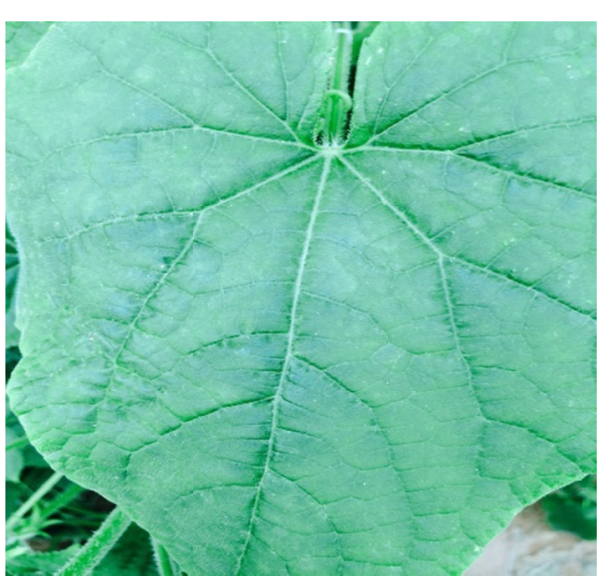

A

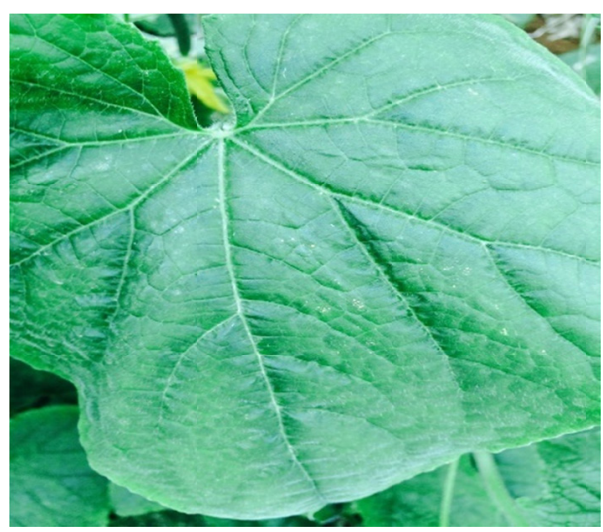

$\mathrm{C}$

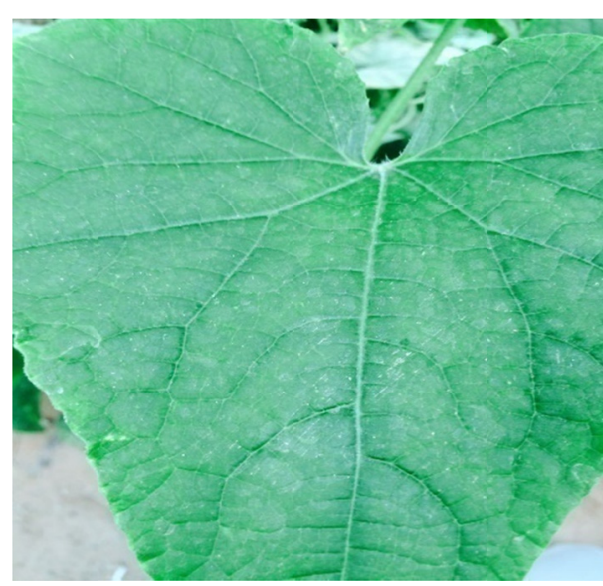

B

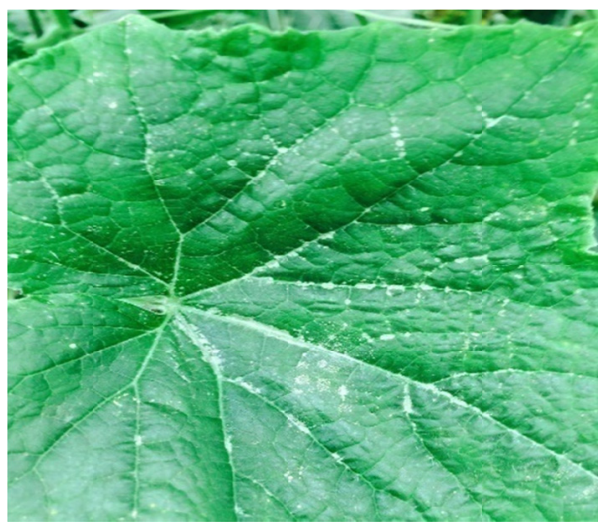

$\mathrm{D}$

Figure 2. Pictures (A 1000 and B 2000 ppm) showing cucumber leaves with no leaf malformation and detectable leaf malformation at (C 3000 and D 4000 ppm) after the field application of Huwa-San TR50 


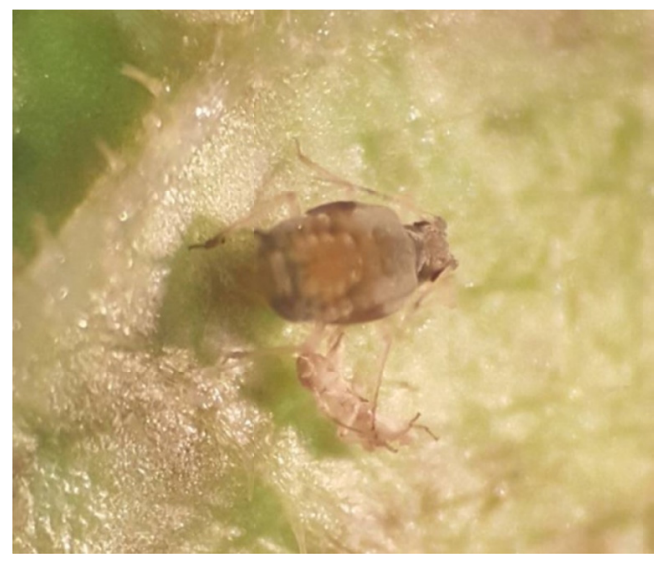

A

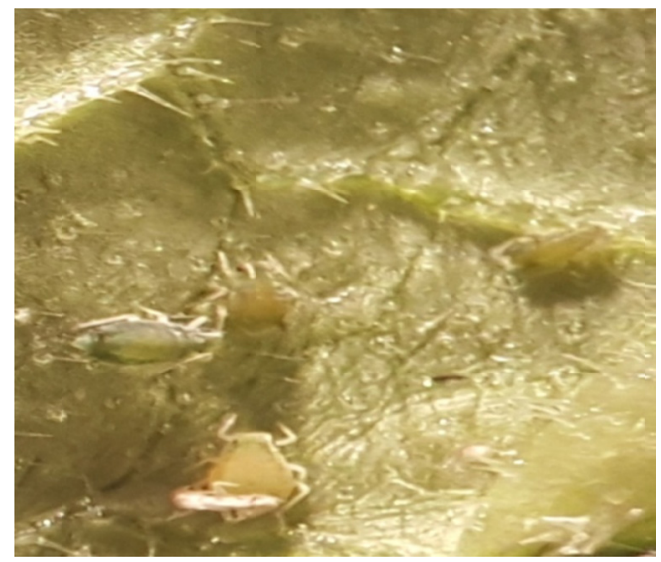

$\mathrm{C}$

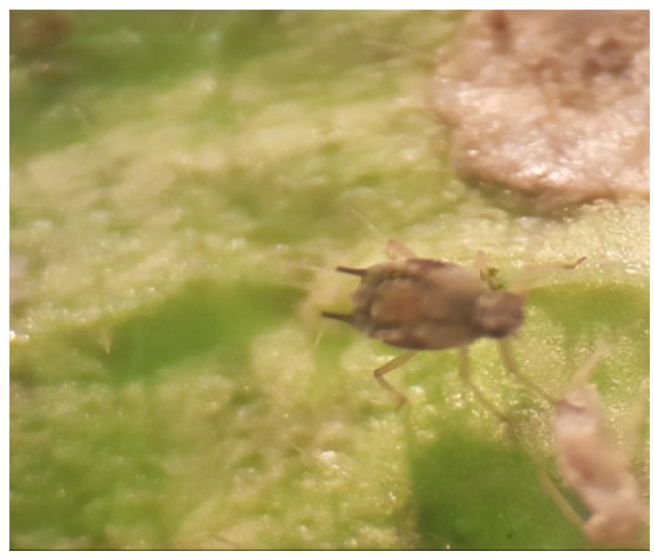

B

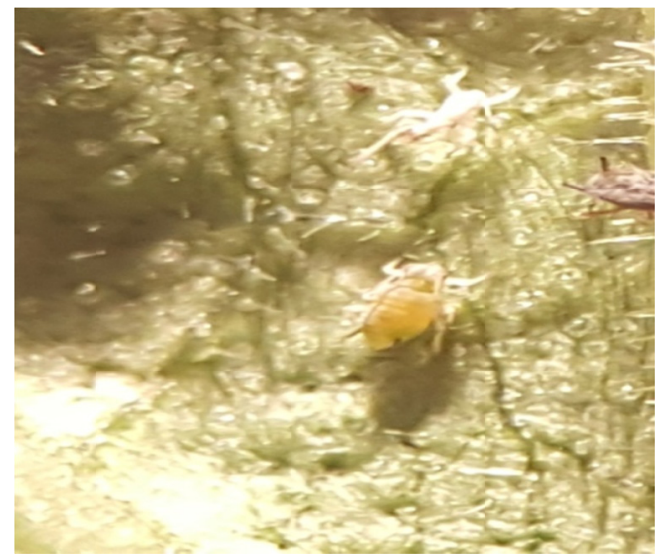

$\mathrm{D}$

Figure 3. Pictures (A) and (B) show the cuticle damage of the treated A. gossypii with $2000 \mathrm{ppm}$ of Huwa-San TR50 as compared with non-treated A. gossypii (control) (C) \& (D)

\section{Discussion}

Many chemical compounds with a range of formulations have been extensively used and sold commercially as insecticides in agriculture. The extensive use of these insecticides might increase insect resistance and affect non-target species, especially when growers exceed the recommended application rate for the control of resistant pests. Also, the excessive use of chemicals can increase insecticide residues in food and the environment. In the last three decades, several previous studies have reported resistance to insecticides in A. gossypii (Funk et al., 1980; Takada \& Murakami, 1988; Grafton-Cardwell et al., 1992; Guburn et al., 1992).

Moores et al. (1996) investigated the resistance of two aphid clones (968E and 1081K) which were originally collected from cotton in Greece in the year 1991 and Zimbabwe in 1992, respectively. They found that the resistance ratios of $968 \mathrm{E}$ as compared with the wild type were $>380$-fold for primicarb, 180-fold for demeton-S-methyl, 5-fold or less for methomyl and 5-fold for pirimiphos-methyl whereas the resistance ratios of $1081 \mathrm{~K}$ were 74 -fold for pirimicarb, 57 -fold for triazamate and 9- to 18 -fold for methomyl and pirimiphos-methyl. These resistance ratios explain the difficulty of controlling $A$. gossypii.

The environmental impacts of insecticide usage as well as the development of resistance to insecticides have encouraged us to investigate a new strategy. The results shown here with Huwa-San TR50 were unexpected, as it can effectively kill $A$. gossypii at certain concentrations whilst having much less effect on non-target/beneficial insects at the same concentrations. Huwa-San TR50 was highly effective in killing A. gossypii and produced mortality of $11.5,42.5,36.0$ and $41.5 \%$ after $24 \mathrm{~h}$ and $93.5,96.5,97.0$ and $95.5 \%$ after $48 \mathrm{~h}$ of exposure at 1000, 2000, 3000 and $4000 \mathrm{ppm}$, respectively. Minimal impacts were recorded for both honeybees and ladybird beetles, although $4000 \mathrm{ppm}$ was lethal to ladybird beetles. It is clear that the exposure of $A$. gossypii to Huwa-San for 48 
h can produce serious and observable damage to the A. gossypii cuticle (Figure 3), thereby resulting in its death. The mode of action here is unknown and requires further investigations to clarify the site and biological basis of Huwa-San TR50 effects.

Huwa-San TR50 concentration of 2000 ppm did not cause malformation of cucumber leaves; however, beyond this concentration a significant leaf malformation was detected (Figure 2). This suggests that $2000 \mathrm{ppm}$ is a safe concentration of Huwa-San TR50, for minimizing the effects on cucumber leaves and retaining the control of $A$. gossypii. This is because there was no statistically significant difference effect on the mortality of $A$. gossypii between 1000, 2000, 3000 and 4000 ppm. Moreover, 2000 ppm of Huwa-San TR50 had no significant effects on the mortality and behavior of both honeybees and ladybird beetles.

As mentioned previously, beneficial insects and natural enemies might be exposed directly or indirectly to insecticides. Hardstone and Scott (2010) reviewed the sensitivity of honeybees to six classes of insecticides (nicotinoids, carbamate, organophosphates, organochlorines, miscellaneous and pyrethroids) as compared with other insect pests. They pointed out that honeybees showed similar sensitivity to these six groups of insecticides as the targeted insect pests. This means that all available insecticides must be used completely to avoid exposing honeybees. Alaux et al. (2010) reported that honeybees exposed to imidacloprid can be significantly weakened resulting in increased mortality by Nosemaceranae infection, such that honeybees exposed to $1 \mathrm{ppb}$ (part per billion) of fipronil and $5.1 \mathrm{ppm}$ of thiacloprid showed an increased level of mortality in $N$. ceranae infection (Vidau et al., 2011). Previous laboratory studies have recorded that the learning and memory capacity of honeybees were affected upon exposure to a high concentration of neonicotinoids (Fairbrother et al., 2014).

Youn et al. (2003) highlighted that both acetamprid and imidacloprid were very toxic to Asian harlequin ladybird beetles (Pallas) (Harmonia axyridis), when applied at the recommended application rate for the control of aphids. In Bangladesh, Mollah et al. (2012) described the mortality of six synthetic chemical insecticides cypermethrin, fenitrothion, fenvalerate, emamectin benzoate, deltamethrin, esfenvalerate, curtap as well as the natural insecticide Neem oil on C. septempunctata.

In this study, honeybees and ladybird beetles were exposed directly to serial concentrations of Huwa-San TR50 up to $4000 \mathrm{ppm}$. They were also indirectly exposed to Huwa-San TR50 by feeding on either treated beeswax (a source of food for honeybees) or aphids (a source of food for ladybird beetles). Thus, both honeybees and ladybird beetles were exposed to Huwa-San TR50 by direct contact and indirectly by feeding. Both treatments had no significant observable effects on mortality and behaviors except for the high mortality of ladybird beetles at the highest concentration tested ( $4000 \mathrm{ppm})$. It is unclear why ladybird beetles were affected by $4000 \mathrm{ppm}$ of Huwa-San TR50. However, in the field the potential of direct exposure of natural enemies and beneficial insects to insecticides is likely to involve indirect exposure at lower concentrations.

A possible limitation to the use of Huwa-San TR50 as a broad spectrum insect control agent is that it does not appear to produce any toxic effects on the larvae or adult male and female red palm weevil (Rhynchophorus ferrugineus) and no observable effects were detected as compared with the control up to $4000 \mathrm{ppm}$ (unpubl result). It is likely that Huwa-San TR50 is much less toxic to tested insects belonging to the order Coleoptera (red palm weevil and ladybird beetles) and the order Hymenoptera (honeybees) whereas it is more toxic to the order Hemiptera (the cotton aphids) and this may reflect differences in the thickness or makeup of the cuticles of these different groups of insects.

\section{Conclusion}

Huwa-San TR50 seems to have the potential of controlling A. gossypii with low toxicity to both honeybees and ladybird beetles. This study has provided evidence showing that $2000 \mathrm{ppm}$ of Huwa-San TR50 is responsible for $96.5 \%$ mortality of $A$. gossypii after $48 \mathrm{~h}$ of exposure and at this concentration there was no observable damage to cucumber leaves or beneficial insects.

Further investigations are required to address the following:

$>$ The potential tree stress that might be produced by Huwa-San TR50.

$>$ The toxicity of Huwa-San TR50 to soil microorganisms, and beneficial animals such as soil dwelling earthworms and nematodes.

$>$ The best time and type of field application of Huwa-San TR50 should be determined, as well as any plant systemic properties.

Finally, the findings encourage us to test the effectiveness of Huwa-San TR50 on other types of aphids, as well as to screen the sensitivity of Huwa-San TR50 on other host plants of cotton aphids. Further studies will be 
necessary to identify its residues in food and the environment.

\section{Acknowledgements}

The author hereby acknowledges Dr. Ian Duce (from the University of Nottingham), for reviewing this paper. The author is very grateful to Dr. Mohamed Motawei for his support and advice during this study.

\section{References}

Aheer, G. M., Munir, M., \& Ali, A. (2006). Screening of wheat cultivars against aphids in ecological conditions of district Mandi Bahaudin. J Agr Res, 44, 55-58.

Alaux, C., Brunet, J.-L., \& Dussaubat, C. (2010). Interactions between Nosema microspores and a neonicotinoid weaken honeybees (Apis mellifera). Environ Microbiol., 12, 774-782. https://doi.org/10.1111/j.1462-2920. 2009.02123.x

Almeida, R. P., Silva, C. D. A., \& Ramalho, F. S. (2008). Integrated management of cotton pests in Brazil. In N. E. M. Beltrao \& D. M. P. Azevedo (Eds.), The cotton agribusiness in Brazil (pp. 1035-1098). Brasília: Embrapa.

Blackman, R. L., \& Eastop, V. F. (1985). Aphids on the Worid's Crops: An identification guide (pp. 35-37). Wiley and Sons, Inc., New York.

De Cock, A., de Clercq, P., Tirry, L., \& Degheele, D. (1996). Toxicity of diafenthiuron and imidacloprid to the predatory bug Podisus maculiventris (Heteroptera: Pentatomidae). Environ. Entomol., 25, 476-480. https://doi.org/10.1093/ee/25.2.476

Deguine, J. P., Goze, E., \& Leclant, F. (2000). The consequences of late outbreaks of the aphid Aphis gossypii in cotton growing in Central Africa: Towards a possible method for the prevention of cotton stickiness. Int. J. Pest Manage., 46(1), 85-89. https://doi.org/10.1080/096708700227426

Ebert, T. A., \& Cartwright, B. (1997). Biology and ecology of Aphis gossypii Glover (Homoptera: Aphididae). Southwest Entomol., 22, 115-153.

Ebert, T. A. (2008). Melon aphid. Aphis gossypii (Hemiptera: Aphididae). In J. L. Capinera (Ed.), Encyclopedia of entomology (Chapter 1-4, pp. 1374-1378). https://doi.org/10.1007/978-1-4020-6359-6_4541

Anonymous. (2013). EU to Restrict 'Bee-Harming’ Pesticides. Wall Street Journal.

European Food Safety Authority. (2013). Conclusion on the peer review of the pesticide risk assessment for bees for the active substance clothianidin. EFSA Journal, 11(1), 3066. https://doi.org/10.2903/j.efsa.2013.3066

Fairbrother, A., Purdy, J., Anderson, T., \& Fell, R. (2014). Risks of neonicotinoid insecticides to honeybees. Environ Toxicol Chem., 33(4), 719-31. https://doi.org/10.1002/etc. 2527

Furk, C., Powell, D. F., \& Heyd, S. (1980). Pirimicarb resistance in the melon and cotton aphid, Aphis gossypii Glover. Plant Pathol., 29, 191-196. https://doi.org/10.1111/j.1365-3059.1980.tb01211.x

Furk, C., \& Hines, C. M. (1993). Aspects of insecticide resistance in the melon and cotton aphid, Aphis gossypii (Hemiptera: Aphididae). Ann. Appl. Biol., 123, 9-17. https://doi.org/10.1111/j.1365-3059.1980.tb01211.x

Hardstone, M. C., \& Scott J. G. (2010). Is Apis mellifera more sensitive to insecticides than other insects? Pest. Manag. Sci., 66, 1171-80. https://doi.org/10.1002/ps.2001

Hollingsworth, R. G., Tabashnik, B. E., Ullman, D. E., Johnson, M. W., \& Messing, R. (1994). Resistance of Aphis gossypii (Homoptera: Aphididae) to Insecticides in Hawaii: Spatial Patterns and Relation to Insecticide Use. J Econ Entomol, 87(2), 293-300. https://doi.org/10.1093/jee/87.2.293

Ishaaya, I., \& Mendelson, Z. (1987). The susceptibility of the melon aphid, Aphis gossypii, to insecticides during the cotton growing season. Hassadeh, 67, 1772.

Kaleem, M. S., Azam, I., Iram, N., Iqbal, W., Rashda, A., Anwer, F., Atta, K., \& Ali, R. (2014). Cotton aphid Aphis Gossypii L. (Homoptera; Aphididae); A Challenging Pest; Biology and Control Strategies: A Review. Int J Appl Biol Pharm., 5(1), 290-294.

Khattak, M. A., Riazuddin, \& Annayatullah, M. (2007). Population dynamics of aphids (Homoptera: Aphididae) on different wheat cultivars and response of cultivars to aphids in respect of yield and yield related parameters. Pak. J. Zool., 39, 109-115.

Leclant, F., \& Deguine, J. P. (1994). Aphids (Hemiptera: Aphididae). In G. A. Mattews, J. P. Tunstall (Eds.), Insect pests of cotton (pp. 285-323). Wallingford: CAB International. 
Moores, G. D., Gao, X., Denholm, I., \& Devonshire, A. L. (1996). Characterisation of Insensitive Acetylcholinesterase in Insecticide-Resistant Cotton Aphids, Aphis gossypii Glover (Homoptera: Aphididae). Pestic. Biochem. Physiol., 56(2), 102-10. https://doi.org/10.1006/pest.1996.0064

Mollah, M. M. I., Rahman, M. M., \& Alam, M. Z. (2012). Toxic Effect of Some Insecticides on Predatory Lady Bird Beetles (Coleoptera: Coccinellidae) in Country Bean (Lablab purpureus L.) field. World J Zool., 7(4), 347-350.

MSTATC, A. (1990). Microcomputer program for the design. Management and analysis of agronomic research experiments. Michigan State University, East Lansing, MI, USA.

Godfrey, L. D., \& Fuson, K. J. (2001). Environmental and Host Plant Effects on Insecticide Susceptibility of the Cotton Aphid (Homoptera: Aphididae). The Journal of Cotton Science, 5, 22-29.

Grafton-Cardwell, E. E. (1991). Geographical and temporal variation in response to insecticides in various life stages of Aphis gossypii (Homoptera: Aphididae) infesting cotton in California. J. Econ. Entomol., 84, 741-749. https://doi.org/10.1093/jee/84.3.741

Grafton-Cardwell, E. E., Godfrey, L. D., Brindley, W. A., \& Goodell, P. B. (1997). Status of Lygus bug and cotton aphid resistance in the San Joaquin Valley. In T. C. Nelson (Ed.), Proceedings of the Beltwide Cotton Production Conference (Vol. 4, pp. 1072-107). New Orleans, LA.

Grafton-Cardwell, E. E., Leigh, T. F., Bentley, W. J., \& Goodell, P. B. (1992). Cotton aphids have become resistant to commonly used pesticides. Calif. Agric., 46, 4-7.

Gubrun, E. E., Delorme, R., Auge, D., \& Moreau, J. P. (1992). Insecticide resistance in cotton aphid Aphis gossypii (Glov.) in the Sudan Gezira. Pestic. Sci., 35, 101-107. https://doi.org/10.1002/ps.2780350202

Pinto, E. S., Barros, E. M., Torres, J. B., Neves, R. C., \& Dos, S. (2013). The control and protection of cotton plants using natural insecticides against the colonization by Aphis gossypii Glover (Hemiptera: Aphididae). Acta Sci. Agron., 35(2), 169-174. https://doi.org/10.4025/actasciagron.v35i2.15764

Saito, T. (1989). Insecticide resistance of the cotton aphid, Aphis gossypii Glover (Homoptera: Aphididae). 1. Susceptibility to several insecticides and esterase activity of field populations collected in Shizuoka Prefecture. Jpn. J. Appl. Entomol. Zool., 33(4), 204-210. https://doi.org/10.1303/jjaez.33.204

Seo, M. J., \& Youn, Y. N. (2000). The Asian ladybird, Harmonia axyridis, as biological control agents: I. Predacious behavior and feeding ability. Kor. J. Appl. Entomol., 39, 59-71.

Seo, M. J., \& Youn, Y. N. (2002). Effective preservation methods of the Asian, Harmonia axyridis (Coleoptera: Coccinellidae), as an application strategy for the biological control of aphid. J. Asia Pacific Entomol, 5, 209-214. https://doi.org/10.1016/S1226-8615(08)60154-5

Sun, Y. Q., Feng, G., Yuan, J. G., Zhu, P., \& Gong, K. (1987). Biochemical mechanism of resistance of cotton aphid to organophosphorous insecticides. Acta Entomol. Sin., 30, 13-20.

Takada, H., \& Murakami, Y. (1988). Esterase variation and insecticide resistance in Japanese Aphis gossypii. Entomol. Exp. Appl., 48, 37-41. https://doi.org/10.1111/j.1570-7458.1988.tb02295.x

Torres, J. B., \& Silva-Torres, C. S. A. (2008). Interaction between insecticides and soil moisture in the control of the aphid and the whitefly in cotton. Brazil J Agri., 43(8), 949-956. https://doi.org/10.1590/ S0100-204X2008000800002

Vidau, C., Diogon, M., Aufauvre, J., Fontbonne, R., Viguès, B., \& Brunet, J.-L. (2011). Exposure to Sublethal Doses of Fipronil and Thiacloprid Highly Increases Mortality of Honeybees Previously Infected by Nosema ceranae. PLoS ONE, 6(6), e21550. https://doi.org/10.1371/journal.pone.0021550

Youn, Y. N., Seo, M. J., Shin, J. G., Jang, C., \& Yu, Y. M. (2003). Toxicity of greenhouse pesticides to multicolored Asian lady beetles, Harmonia axyridis (Coleoptera: Coccinellidae). Biol Control., 28(2), 164-70. https://doi.org/10.1016/S1049-9644(03)00098-7

Zheng, B. Z. X., Gao, W., Wang, Z. G., \& Cao, B. J. (1988). Preliminary studies of pyrethroid resistance in melon-cotton aphid (Aphis gossypii Glover) in Beijing suburbs and northern region of Hebei province. Acta Phytophyl. Sin., 15, 55. 


\section{Copyrights}

Copyright for this article is retained by the author(s), with first publication rights granted to the journal.

This is an open-access article distributed under the terms and conditions of the Creative Commons Attribution license (http://creativecommons.org/licenses/by/4.0/). 